\section{Periodontal disease might be associated even with impaired fasting glucose}

\author{
Y. Zadik, ${ }^{1}$ R. Bechor, ${ }^{2}$ S. Galor ${ }^{3}$ and L. Levin ${ }^{4}$
}

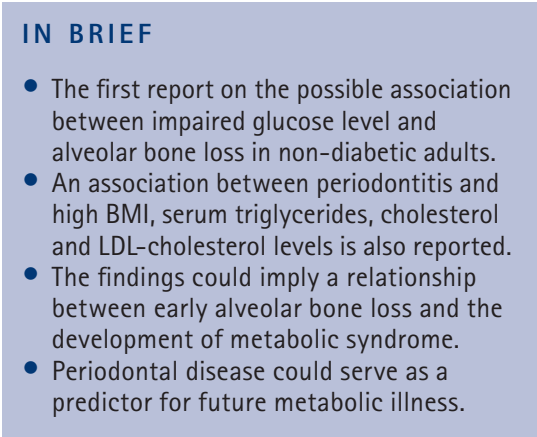

\begin{abstract}
Objective To determine whether there is an association between fasting plasma glucose level and periodontal condition in a non-diabetic male population. Methods Data of periodic medical examinations of 815 non-diabetic male adults (mean age $38.1 \pm 7.0$ years) were analysed. Blood samples were drawn from each subject following a 14-hour fast. The distance between the cement-enamel-junction to alveolar bone crest was measured at inter-proximal sites on two standardised posterior bitewing radiographs. Results Higher prevalence of alveolar bone loss was found among individuals with a fasting glucose level of $\geq 100 \mathrm{mg} / \mathrm{dL}$ than among individuals with $<100 \mathrm{mg} / \mathrm{dL}(\mathrm{p}=0.032)$ and among individuals with BMI $\geq 25$ than among individuals with $\mathrm{BMI}<25(\mathrm{p}=0.025)$. Associations were found between bone loss prevalence and serum triglyceride levels of $\geq 200 \mathrm{mg} / \mathrm{dL}$, total cholesterol level of $\geq 200 \mathrm{mg} / \mathrm{dL}$ and LDL-cholesterol level of $\geq 130 \mathrm{mg} / \mathrm{dL}$ ( $p=0.010$, $p<0.001, p=0.009$, respectively). Conclusions In the studied non-diabetic adult population, periodontal disease was associated with impaired glucose level. Periodontal disease could serve as a predictor for future diabetes mellitus, or play a possible role in the glucose imbalance and diabetes mellitus development.
\end{abstract}

\section{INTRODUCTION}

Periodontitis, a chronic infectious disease of the supporting tissues of the teeth, is caused by colonisation of the periodontal tissues by a complex mix of anaerobic, gram-negative bacteria and, to a lesser extent, gram-positive bacteria. The inflammatory reaction causes slow progression of alveolar (periodontal) bone loss. If untreated, teeth lose their alveolar bone support, become mobile and eventually exfoliate. Periodontitis, a major cause of tooth loss among adults, results in reduced oral function and quality of life. ${ }^{1}$

An emerging concept in the dental literature is 'periodontal medicine', which deals with the association between periodontal inflammation and systemic conditions.

\footnotetext{
${ }^{*}$-3Physicians, The Center for Health Promotion and Preventive Medicine, Medical Corps, Israel Defense Forces, Jerusalem, Israel; " Senior Physician, Department of Periodontology, School of Graduate Dentistry, Rambam Health Care Campus, Haifa, Israel

${ }^{*}$ Correspondence to Dr. Y. Zadik

Email:yzadik@gmail.com
}

\section{Online artcile number E20}

Refereed Paper - accepted 2 July 2009

DOI: 10.1038/sj.bdj.2010.291

${ }^{\circledR}$ British Dental Journal 2010; 208: E20
According to the current literature, periodontitis is associated with coronary heart disease (CHD) ${ }^{2}$ and cerebral ischaemia. ${ }^{3}$ Preterm low-weight birth, chronic obstructive pulmonary disease and erectile dysfunction ${ }^{4}$ were also associated with periodontitis.

A bi-directional association between periodontitis and diabetes mellitus (DM) has been established in the literature. DM adversely affects periodontal condition and periodontitis adversely affects glycaemic control, increasing the risk of complications in the diabetic patient. ${ }^{5}$ Hyperglycaemia and consequently advanced glycation endproducts (AGEs) induce oxidation stress. This oxidation stress contributes to chronic monocytic upregulation and secretion of cytokines (eg TNF- $\alpha$, IL- 1 $\beta$ and IL-6) that involve inflammation and destruction of the periodontium. ${ }^{5}$ Blockade of AGE-receptors reduces the bacterial-induced alveolar bone loss in diabetic mice. ${ }^{6}$

Although the amplification effect between DM and periodontitis is well established, ${ }^{5}$ rarely studied is the relationship between periodontal condition and plasma glucose level in non-diabetic individuals. Katz et al. ${ }^{7}$ studied the relationship between periodontal treatment needs as measured by the World Health Organisation's CPITN method and plasma glucose level in a healthy adult population. In their cohort, male individuals with greater periodontal treatment needs had an increased average fasting plasma glucose level $(95.0 \mathrm{mg} / \mathrm{dL})$ compared to individuals with reduced periodontal needs (91.49 mg glucose/dL, p <0.0001). The effect was pronounced, especially in individuals with body mass index (BMI) $\geq 25 \mathrm{~kg} / \mathrm{m}^{2}$. No such relationship between periodontal treatment need and glucose level was found in female adults. ${ }^{7}$ Since hyperlipidaemia was previously associated with periodontal inflammation, ${ }^{8}$ it was postulated that the DM-related elevation in plasma triglycerides was the linkage between DM and alveolar bone destruction. ${ }^{7-9}$ However, it is controversial whether there is an association between periodontal condition and metabolic syndrome and BMI. ${ }^{10,11}$

The aim of the present study was to further examine the association between fasting plasma glucose level and alveolar bone condition in a non-diabetic male population. BMI, triglycerides and cholesterol levels were also examined. 


\section{METHODS}

\section{Subjects}

The Israel Defence Forces personnel older than 25 years of age are required to take periodic medical examinations at 3- to 5-year intervals. Data of periodic examinations of male adults were analysed.

\section{Measurement of metabolic parameters}

Each subject completed a detailed questionnaire assessing demographic, nutritional, lifestyle, and medical factors. Blood samples were drawn after a 14-hour fast and analysed. A trained medical technician measured height and weight, and a physician performed a complete physical examination. Individuals with pre-existing diagnosed DM and/or fasting glucose level $>126 \mathrm{mg} / \mathrm{dL}$ were excluded from further analysis.

\section{Assessment of periodontal condition}

Measurements of the alveolar bone height were performed by two experienced dentists ( $\mathrm{YZ}$ and $\mathrm{RB}$ ) from two bilateral pairs of standardised posterior bitewing dental radiographs in each individual. The distance between the cement-enamel junction (CEJ) and the alveolar bone crest was measured at interproximal sites from the distal aspect of the first premolars to the mesial aspect of the second molars. Measurements were made with the aid of a viewing box and a magnifying lens. For statistical analysis, periodontitis was defined when distance $\geq 6 \mathrm{~mm}$ between CEJ and alveolar bone crest was measured in at least one site. ${ }^{12,13}$ The examiners were blinded to the metabolic values of the subjects at the time of alveolar bone evaluation. Disagreements were resolved by discussion.

\section{Statistical analysis}

BMI was calculated by dividing the weight in kilograms by the square of the height in metres. Continuous variables were expressed by mean \pm standard deviation. The Student's t-test was used to compare the mean parametric variables between individuals with periodontitis and individuals without periodontitis. The $\chi^{2}$-test was used to compare the prevalence of non-parametric variables between these

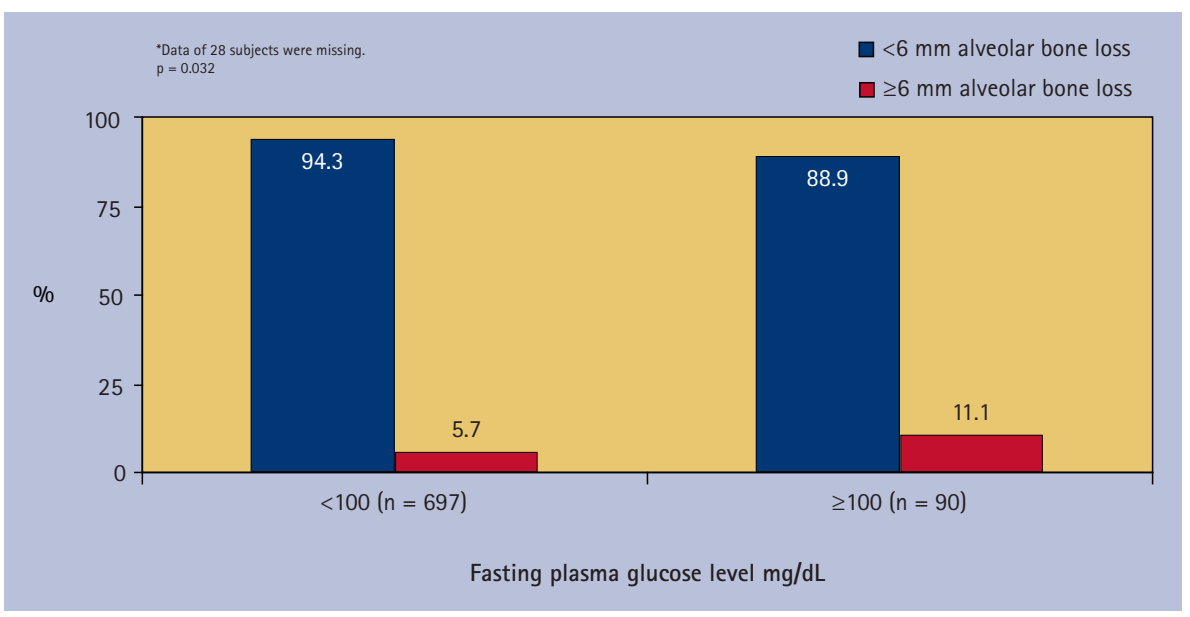

Fig. 1 Alveolar bone loss by fasting plasma glucose level*

Table 1 Prevalence of alveolar bone loss by levels of fasting serum triglycerides, (total) cholesterol, LDL and HDL cholesterol

Metabolic parameter \begin{tabular}{l|l|l} 
Low & High & $\mathrm{p}$ value
\end{tabular}

Fasting serum triglycerides level

\begin{tabular}{|l|l|l|l}
\hline Values, $\mathrm{mg} / \mathrm{dL}$ & $<200$ & $\geq 200$ & \\
\hline $\mathrm{N}^{*}$ & 672 & 117 & \\
\hline Prevalence of bone loss $\geq 6 \mathrm{~mm}$ & $6.1 \%$ & $8.6 \%$ & 0.010 \\
\hline
\end{tabular}

Fasting (total) cholesterol level

\begin{tabular}{|c|c|c|c|}
\hline Values, mg/dL & $<200$ & $\geq 200$ & \\
\hline $\mathrm{N}^{\ddagger}$ & 448 & 338 & \\
\hline Prevalence of bone loss $\geq 6 \mathrm{~mm}$ & $4.2 \%$ & $9.5 \%$ & $<0.001$ \\
\hline \multicolumn{4}{|l|}{ Fasting LDL cholesterol level } \\
\hline Values, mg/dL & $<130$ & $\geq 130$ & \\
\hline $\mathrm{N}^{5}$ & 441 & 299 & \\
\hline Prevalence of bone loss $\geq 6 \mathrm{~mm}$ & $4.5 \%$ & $7.7 \%$ & 0.009 \\
\hline \multicolumn{4}{|l|}{ Fasting HDL cholesterol level } \\
\hline Values, mg/dL & $<60$ & $\geq 60$ & \\
\hline$N^{\prime \prime}$ & 720 & 57 & \\
\hline Prevalence of bone loss $\geq 6 \mathrm{~mm}$ & $6.7 \%$ & $5.3 \%$ & 0.464 \\
\hline $\begin{array}{l}\text { *Data of } 26 \text { subjects were missing. } \\
\text { †Data of } 29 \text { subjects were missing. } \\
\text { §Data of } 75 \text { subjects were missing. } \\
\text { ||Data of } 38 \text { subjects were missing. }\end{array}$ & & & \\
\hline
\end{tabular}

two groups. The $\chi^{2}$-test was also used to evaluate the statistical differences between alveolar bone loss by severity levels of metabolic values. Statistical significance was accepted at the probability level of $\mathrm{p}<0.05$. Data were analysed by SPSS 12.0 (SPSS Inc., Chicago, IL, USA).

\section{RESULTS}

The analysis included 815 adults who met the inclusion criteria. The mean age $( \pm S D)$ of subjects was $38.1( \pm 7.0)$ years. Fifty-five
(6.7\%) subjects had $\geq 6 \mathrm{~mm}$ alveolar bone loss. Age was positively associated with alveolar bone loss ( $\mathrm{p}<0.0001$ ).

Individuals with fasting glucose level $\geq 100$ (but <126) mg/dL had a higher prevalence of bone loss $\geq 6 \mathrm{~mm}$ than other individuals (Fig. $1 ; p=0.032$ ). Other glucose cut levels (82, 87, 91 and $95 \mathrm{mg} / \mathrm{dL}$ ) did not yield significant differences in bone loss proportions.

Individuals with $\mathrm{BMI} \geq 25 \mathrm{~kg} / \mathrm{m}^{2}$ had a higher prevalence of bone loss than 


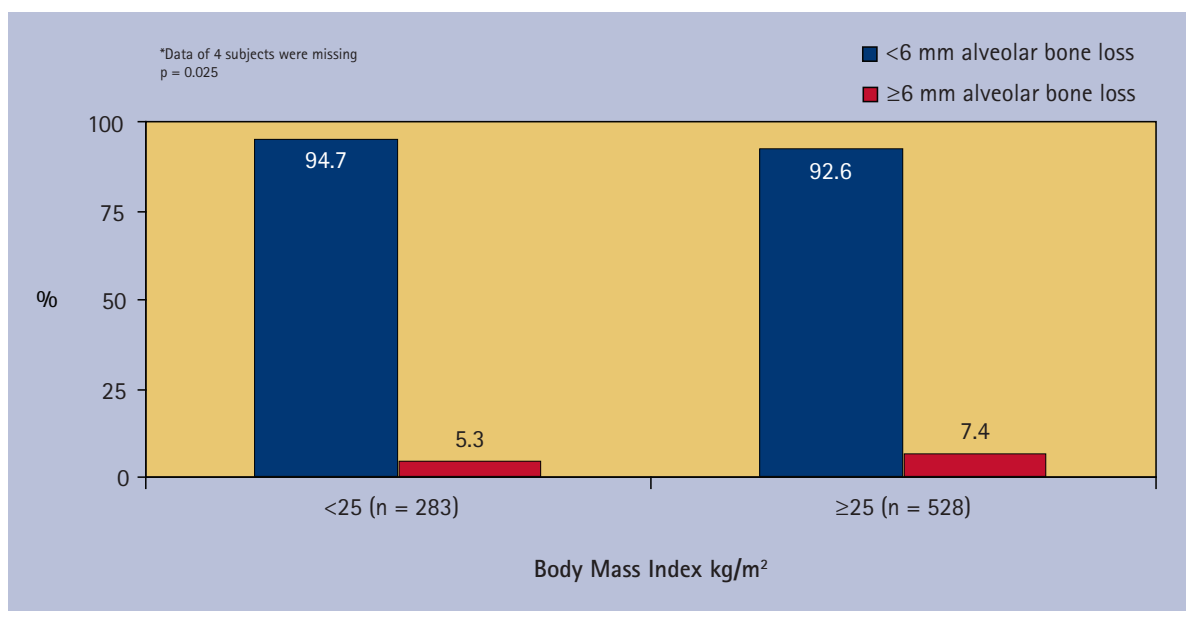

Fig. 2 Alveolar bone loss by BMI*

other individuals (Fig. $2 ; \mathrm{p}=0.025$ ). Associations were also found between fasting serum triglyceride levels of $\geq 200 \mathrm{mg} /$ $\mathrm{dL}$, total cholesterol level of $\geq 200 \mathrm{mg} / \mathrm{dL}$ and LDL-cholesterol level of $\geq 130 \mathrm{mg} /$ $\mathrm{dL}$, and prevalence of alveolar bone loss ( $p=0.010, p<0.001, p=0.009$, respectively). There was no association between high density lipoprotein (HDL)-cholesterol level and bone loss ( $\mathrm{p}=0.464$, Table 1$)$.

\section{DISCUSSION}

Compelling evidence has identified a series of metabolic parameters that cluster together and predispose to serious systemic diseases, such as DM or CHD. Approximately 15 years ago, these factors were grouped together to describe the socalled 'Syndrome X'. Today, co-existence of the same metabolic factors, including obesity, dyslipidaemia, insulin resistance, high blood pressure and a pro-inflammatory and pro-thrombotic state, define the metabolic syndrome. ${ }^{14}$ Individuals with metabolic syndrome exhibit an increased risk of $\mathrm{DM}^{15}$ and CHD. ${ }^{16}$ New treatment strategies are being tested to tackle this risk by reducing the specific factors leading to the metabolic syndrome. ${ }^{17}$

Low-grade systemic inflammation might represent one of the aetiologic factors behind the metabolic syndrome. Indeed inflammatory bio-markers are predictors of future risk of diabetes, ${ }^{15} \mathrm{CHD},{ }^{18}$ and metabolic syndrome. ${ }^{14}$

In this cross-sectional study, a significant association was found between periodontal infection-related bone loss and fasting glucose level among non-diabetic male adults. Evaluation of alveolar bone level on posterior intra-oral bitewing radiographs, as in the present study, is one of the most effective methods for surveying periodontal disease in large-scale studies. ${ }^{12,13}$ The present study focused on male adults according the results of Katz et al. ${ }^{7}$ Moreover, alveolar bone loss was also related to BMI, serum triglyceride levels, cholesterol and LDL-cholesterol levels. These parameters are components in the definition of metabolic syndrome, which include abdominal obesity, triglyceride level, cholesterol level, blood pressure, and fasting blood sugar level. It is possible that there is a relation between early alveolar bone loss and the development of metabolic syndrome.

A fasting plasma glucose level of $>126 \mathrm{mg} / \mathrm{dL}$ has been used to diagnose DM. However, according to the Expert Committee on the Diagnosis and Classification of Diabetes Mellitus of the American Diabetes Association, an impaired fasting plasma glucose level of above $100 \mathrm{mg} / \mathrm{dL}$ is currently considered. ${ }^{19}$ Elevated fasting plasma glucose level $(\geq 100 \mathrm{mg} / \mathrm{dL}$ ) in young adults may predict type 2 diabetes in older age, more than fasting plasma glucose level of $<100 \mathrm{mg} /$ $\mathrm{dL}^{20,21}$ The present results revealed a higher occurrence of alveolar bone loss in subjects with elevated (although still considered non-diabetic) fasting glucose level of $\geq 100 \mathrm{mg} / \mathrm{dL}$. Thus, periodontal disease might serve as a predictor for future DM, or as a possible causative factor for impaired glucose balance and the development of DM. However, more longitudinal research is needed to evaluate the actual relationship between these two situations.

The major limitation of this study was the studied military personnel cohort that may be considered representative of a unique group of healthy young men. ${ }^{22}$ However, the characteristics of the population are strikingly similar to cohorts in other studies of young men, regarding blood glucose, DM, and periodontal conditions. ${ }^{7,21}$ Another limitation was the number of subjects $(\mathrm{n}=815)$ which did not enable further statistical analysis of the influence of confounders and co-factors. A larger-scale study with confounder analysis and a follow-up study in these subjects to examine whether periodontal disease is predisposed to older-age DM are warranted.

\section{CONCLUSIONS}

In this cross-sectional study, a significant association was found between periodontal infection-related bone loss and fasting glucose level among Israeli non-diabetic male adults. Moreover, alveolar bone loss was related to BMI, serum triglyceride levels, cholesterol and LDL-cholesterol levels, which are major components in the definition of metabolic syndrome. These findings could imply that there is a relation between early alveolar bone loss and the development of metabolic syndrome. Further long-term longitudinal studies are warranted.

The authors would like to thank Tzipi Shochat for statistical evaluation.

1. Pihlstrom B L, Michalowicz B S, Johnson N W. Periodontal diseases. Lancet 2005; 366: 1809-1820.

2. Mattila K J, Pussinen P J, Paju S. Dental infections and cardiovascular diseases: a review. J Periodontol 2005; 76: 2085-2088.

3. Grau A J, Becher $H_{\text {, Ziegler } C M}$ et al. Periodontal disease as a risk factor for ischemic stroke. Stroke 2004; 35: 496-501.

4. Zadik Y, Bechor R, Galor S, Justo D, Heruti R J. Erectile dysfunction might be associated with chronic periodontal disease: two ends of the cardiovascular spectrum. J Sex Med 2009; 6: 1111-1116.

5. Taylor G W, Borgnakke W S. Periodontal disease: associations with diabetes, glycemic control and complications. Oral Dis 2008; 14: 191-203.

6. Lalla E, Lamster I B, Feit M et al. Blockade of RAGE suppresses periodontitis-associated bone loss in diabetic mice. J Clin Invest 2000; 105: 1117-1124.

7. Katz J, Chaushu G, Sgan-Cohen H D. Relationship of blood glucose level to community periodontal index of treatment needs and body mass index in a permanent Israeli military population. J Periodontol 2000; 71: 1521-1527.

8. Cutler C W. Shinedling E A, Nunn M et al. Association between periodontitis and hyperlipidemia: cause or effect? J Periodontol 1999; 70: 1429-1434.

9. Cutler C W, Machen R L, Jotwani R, lacopino A M. Heightened gingival inflammation and attachment loss in type 2 diabetics with hyperlipidemia. J Periodontol 1999; 70: 1313-1321.

10. Janket $S \mathrm{~J}$, Jones J A, Meurman J H, Baird A E, Van Dyke T E. Oral infection, hyperglycemia, and endothelial dysfunction. Oral Surg Oral Med Oral Pathol Oral Radiol Endod 2008; 105: 173-179.

11. Pischon N, Heng N, Bernimoulin J P, Kleber B M, 
Willich S N, Pischon T. Obesity, inflammation, and periodontal disease. J Dent Res 2007; 86: 400-409.

12. Mol A. Imaging methods in periodontology. Periodontol 2000 2004; 34: 34-48.

13. Merchant A T, Pitiphat W, Parker J, Joshipura K Kellerman M, Douglass C W. Can nonstandardised bitewing radiographs be used to assess the presence of alveolar bone loss in epidemiologic studies? Community Dent Oral Epidemiol 2004; 32: 271-276.

14. Grundy S M, Brewer H B, Cleeman J I, Smith S C, Lenfant $\mathrm{C}$. Definition of metabolic syndrome - report of the national heart, lung, and blood institute/American Heart Association Conference on scientific issues related to definition. Arterioscler Thromb Vasc Biol 2004; 24: E13-E18.
15. Fernandez-Real J M, Ricart W. Insulin resistance and chronic cardiovascular inflammatory syndrome. Endocr Rev 2003; 24: 278-301.

16. Bestermann W, Houston M C, Basile J et al. Addressing the global cardiovascular risk of hypertension, dyslipidemia, diabetes mellitus, and the metabolic syndrome in the Southeastern United States, part II: treatment recommendations for management of the global cardiovascular risk of hypertension, dyslipidemia, diabetes mellitus, and the metabolic syndrome. Am J Med Sci 2005; 329: 292-305.

17. Deen D. Metabolic syndrome: time for action. Am Fam Physician 2004; 69: 2875-2882.

18. Madjid M, Awan I, Willerson J T, Casscells S W. Leukocyte count and coronary heart disease implications for risk assessment. J Am Coll Cardiol
2004; 44: 1945-1956.

19. Genuth S, Alberti K G, Bennett P et al. Follow-up report on the diagnosis of diabetes mellitus. Diabetes Care 2003; 26: 3160-3167.

20. Tai ES, Goh S Y, Lee J J et al. Lowering the criterion for impaired fasting glucose: impact on disease prevalence and associated risk of diabetes and ischemic heart disease. Diabetes Care 2004; 27: 1728-1734.

21. Tirosh A, Shai I, Tekes-Manova D et al. Normal fasting plasma glucose levels and type 2 diabetes in young men. N Engl J Med 2005; 353: 1454-1462.

22. Zadik Y, Zusman S P, Galor S, Dinte A F. Dental attendance and self-assessment of dental status by Israeli military personnel according to gender, education, and smoking status, 1998-2006. Mil Med 2009; 174: 197-200. 